\title{
Mannose binding lectin plays a crucial role in innate immunity against yeast by enhanced complement activation and enhanced uptake of polymorphonuclear cells
}

\author{
Eveline C van Asbeck*1, Andy IM Hoepelman1,2, Jelle Scharringa1, \\ Bjorn L Herpers ${ }^{1,3}$ and Jan Verhoef ${ }^{1}$
}

Address: ${ }^{1}$ Eijkman-Winkler Institute for Medical \& Clinical Microbiology, Utrecht University Hospital, Utrecht, the Netherlands, ${ }^{2}$ Department of Internal Medicine \& Infectious Diseases, Utrecht University Hospital, Utrecht, the Netherlands and ${ }^{3}$ Department of Medical Microbiology \& Immunology, St. Antonius Hospital Nieuwegein, the Netherlands

Email: Eveline C van Asbeck* - E.C.vanAsbeck@umcutrecht.nl; Andy IM Hoepelman - A.I.M.Hoepelman@umcutrecht.nl; Jelle Scharringa - j.scharringa@umcutrecht.nl; Bjorn L Herpers - b.herpers@Antonius.net; Jan Verhoef - j.verhoef@umcutrecht.nl

* Corresponding author

Published: 18 December 2008

BMC Microbiology 2008, 8:229 doi:10.1 186/147|-2180-8-229
Received: 3 June 2008

Accepted: 18 December 2008

This article is available from: http://www.biomedcentral.com//47/-2/80/8/229

(C) 2008 van Asbeck et al; licensee BioMed Central Ltd.

This is an Open Access article distributed under the terms of the Creative Commons Attribution License (http://creativecommons.org/licenses/by/2.0), which permits unrestricted use, distribution, and reproduction in any medium, provided the original work is properly cited.

\begin{abstract}
Background: Mannose binding lectin (MBL) is an important host defence protein against opportunistic fungal pathogens. This carbohydrate-binding protein, an opsonin and lectin pathway activator, binds through multiple lectin domains to the repeating sugar arrays displayed on the surface of a wide range of clinically relevant microbial species. We investigated the contribution of $M B L$ to antifungal innate immunity towards $C$. parapsilosis in vitro.

Results: High avidity binding was observed between MBL and $C$. albicans and $C$. parapsilosis. Addition of MBL to MBL deficient serum increased the deposition of $C 4$ and $C 3 \mathrm{~b}$ and enhanced the uptake of $C$. albicans, $C$. parapsilosis and acapsular $C$. neoformans by polymorphonuclear cells (PMNs). Compared to other microorganisms, such as Escherichia coli, Staphylococcus aureus and Cryptococcus neoformans, $C$. parapsilosis and Candida albicans were potent activators of the lectin pathway.
\end{abstract}

Conclusion: Our results suggest that MBL plays a crucial role in the innate immunity against infections caused by yeast by increasing uptake by PMN.

\section{Background}

Mannose binding lectin [1], a plasma protein of hepatic origin that belongs to the family of calcium-dependent collagenous lectins (collectin), is an important protein of the innate immune system [1-6]. This carbohydrate-binding protein binds mannose and $\mathrm{N}$-acetylglucosamine (GlcNAc) sugars and their derivates present on the surface of a wide range of clinically relevant microbial species and has the ability to distinguish self from nonself $[4,5,7,8]$.
MBL initiates the lectin pathway of complement using attached mannose binding lectin-associated serine proteases (MASP-2) in an antibody- and C1q-independent manner $[5,7,9]$. MASP-2 is indistinguishable in specificity from the convertases found in the classical and alternative of complement activation and permits cleavage of $\mathrm{C} 4$ and C2 to form a C3 convertase $[3,5,7,10]$. Once it has bound, MBL is able to deploy a variety of anti-microbial activities, such as microbial opsonization and/or microbial lysis via 
membrane attack complexes $[8,11]$. However, it is unclear whether MBL acts as a direct opsonin or is merely enhances other complement pathways and/or antibodymediated phagocytosis [5].

MBL deficiency, due to variation in the MBL gene, is one of the most common immunodeficiencies [5,12] and is associated with impaired phagocytosis by polymorphonuclear leukocytes and with an increased burden of infections, especially in immunocompromised individuals [13-15].

The clinically relevant opportunistic microorganism $C$. parapsilosis is now the second or third most common cause of systemic fungal infections after C. albicans [16-19]. It is especially prevalent in very low birth weight neonates, transplant patients, post-surgical patients, patients receiving intravenous hyperalimentation and patients with indwelling invasive devices [20-23]. Most patients at risk have some degree of immunosuppression. MBL has been shown to play a role in the first-line defence against $C$. albicans [9]. The fungal cell wall, which consists mainly of polymers of $N$-acetylglucosamine (chitin), glucose ( $\beta$-glucan) and mannose (mannan) $[15,24]$ is a candidate ligand for MBL and may be capable of activating the lectin complement pathway.

In this study we evaluated the role of $\mathrm{MBL}$ in the opsonophagocytosis of C. parapsilosis. MBL was found to be a crucial opsonin for optimal phagocytosis of C. parapsilosis, C. albicans and acapsular C. neoformans. Sera of patients with MBL deficiency have decreased opsonic capacity.

\section{Methods \\ Microbial strains}

A clinical isolate of Candida parapsilosis strain 05-173 (California Institute for Medical Research, San Jose, CA), as a reference Candida albicans strain ATCC 14053 (American Type Culture Collection), the thinly $(<0.5 \mathrm{~mm})$ encapsulated Cryptococcus neoformans strain NIH 37 (National Institute of Health, Bethesda, MD) and an acapsular mutant of C. neoformans, CAP 67 (E.S. Jacobson, Medical College of Virginia) Staphylococcus aureus Mu 50 (Japanese Collection of Staphylococcus Cultures (JCSC)), S. aureus KV 39 and KV 68 (clinical isolates from University Medical Centre Utrecht), Escherichia coli ATCC 25922 and E. coli ATCC 35218 (American Type Culture Collection) were used. In addition, Saccharomyces cerevisiae was used as a standard reference for the functional MBL test. Isolates were stored at $-80^{\circ} \mathrm{C}$ in $40 \%$ glycerol. Before tests were performed, yeast strains were cultured overnight at $35^{\circ} \mathrm{C}$ on Sabouraud Dextrose Agar (SDA) and bacterial strains were cultured overnight at $37^{\circ} \mathrm{C}$ on blood agar and then kept at $4^{\circ} \mathrm{C}$.

\section{Binding of $M B L$}

Microorganisms $\left(2 \times 10^{7}\right.$ cells $\left./ \mathrm{mL}\right)$ were incubated with 5 $\mu \mathrm{g} / \mathrm{mL}$ of purified human MBL (90\%) (HSR 003; Staten Serum Institut; MBL was purified in a two-step process by, affinity chromatography and gel filtration, with selecting for functionally active and oligomeric MBL. MASPs remain associated and co-elute with MBL [6]) in a total volume of $50 \mu \mathrm{L}$ of veronal-buffered saline $\mathrm{pH} 7.4$, containing $\mathrm{Ca}^{2+}$ and $\mathrm{Mg}^{2+}$ plus $0.05 \% \mathrm{BSA}\left(\mathrm{VSB}^{2+}\right)$, on a shaking plate $(150 \mathrm{rev} / \mathrm{min})$ at $37^{\circ} \mathrm{C}$ for $30 \mathrm{~min}$. Organisms were spun down for $5 \mathrm{~min}$ at $15000 \mathrm{rpm}$ and the pellets were washed with $\mathrm{VSB}^{2+}$ before suspension with mouse anti-MBL monoclonal antibody (mAbs) $(10 \mu \mathrm{g} / \mathrm{mL}$ in VSB$^{2+}$; HYB131-010; Antibody shop, Staten Serum Institute, Copenhagen, Denmark). After a 30-min incubation on ice, samples were centrifuged and washed as described above and were resuspended in FITC-labelled goat anti mouse IgG (DakoCytomation, Glostrup, Denmark) (80 $\mu \mathrm{g} / \mathrm{mL}$ in PBS) and incubated on ice for $30 \mathrm{~min}$. Suspensions were centrifuged and washed as described above. Samples were analyzed by flow cytometry (FACSCaliber, Becton Dickinson; Mountain View, CA) with measurement of mean fluorescence intensity (MFI). Experiments were done in duplicate and repeated at least three times. Negative controls were established for MBL binding by the omission of MBL. In order to evaluate whether the binding observed by C-type lectin interactions, inhibition experiments using a calcium chelating agent $20 \mathrm{mmol} / \mathrm{L}$ EDTA was added to the MBL solution $5 \mathrm{~min}$ before the addition of MBL to the microorganisms.

\section{Deposition of C4, and C3b}

MBL-deficient serum was obtained from a subject who was homozygous for the LYPB haplotype of the MBL gene and had undetectable levels of serum MBL $(<0.05 \mu \mathrm{g} /$ $\mathrm{mL}$ ). Serum IgG was depleted from the MBL-deficient serum using a HiTrap Protein G column (GE Healthcare, Uppsala, Sweden) [25]. The freshly prepared MBL-deficient serum samples were aliqouted and stored at $-70^{\circ} \mathrm{C}$ until use. Informed consent was obtained from the donor.

Microorganisms $\left(2 \times 10^{6}\right.$ cells $\left./ \mathrm{mL}\right)$ were incubated in 50 $\mu$ HBS $^{2+}$ (Hepes-buffered saline, $20 \mathrm{mM}$ Hepes, $140 \mathrm{mM}$ $\mathrm{NaCl}, 5 \mathrm{mM} \mathrm{CaCl}_{2}$ and $2.5 \mathrm{mM} \mathrm{MgCl}_{2}$ ) containing $10 \%$ MBL-deficient serum supplemented with anti-C1q mAb (50 $\mu \mathrm{g} / \mathrm{mL}$; Sanquin, Amsterdam, The Netherlands) to inhibit the classical pathway [26] and with or without purified human MBL $(2.5 \mu \mathrm{g} / \mathrm{mL})$, in a sterile 96 well plate incubated for 2, 5, 15 and 30 minutes at a shaking plate $(150 \mathrm{rev} / \mathrm{min})$ at $37^{\circ} \mathrm{C}$. The reaction in each well was stopped by adding $150 \mu \mathrm{L}$ of ice-cold PBS. Suspensions were washed and centrifuged for $10 \mathrm{~min}$ at 3500 rpm. The supernatants were removed, and the pellets were suspended with $50 \mu \mathrm{L}$ of a solution of murine monoclonal anti-human C4d (Quidel, San Diego, CA) (4 $\mu \mathrm{g} /$ 
$\mathrm{mL}$ in PBS). After a 30-min incubation on ice, the samples were centrifuged and washed as described above and the pellets were resuspended in FITC-labelled goat antimouse IgG (DakoCytomation, Glostrup, Denmark) (80 $\mu \mathrm{g} / \mathrm{mL}$ in PBS) and were incubated on ice for $30 \mathrm{~min}$. Suspensions were centrifuged and washed as described above and measured by flow cytometry. C4d deposition was evaluated in duplicate and repeated at least three times.

C3b deposition was analyzed by incubation of the organisms with $10 \%$ MBL-deficient sera in $\mathrm{HBS}^{2+}$, after which surface-bound C3b was detected with FITC-conjugated $\left(\mathrm{Fab}^{\prime}\right)_{2}$ anti-human C3 (Protos Immunoresearch, San Francisco, CA) $(20 \mu \mathrm{g} / \mathrm{mL}$ in PBS). Detection of C3b deposition was the same as for deposition of C4d.

\section{Preparation of Polymorphonuclear Leukocytes}

Human polymorphonuclear (PMN) cells were isolated from the blood of healthy volunteers using a Ficoll/Histopaque gradient with sodium heparin as anticoagulant (Greiner, Alphen a/d Rijn, The Netherlands) as described previously [27]. In brief, heparinized blood was diluted with an equal volume of PBS ( $\mathrm{pH} 7.4$ ), layered onto a gradient of Ficoll-Paque PLUS (GE Healthcare, Uppsala, Sweden) and Histopaque-1119 (Sigma-Aldrich, Steinheim, Germany), and centrifuged for 20 minutes at $400 \times g$. Neutrophils were collected from the Histopaque layer and washed with RPMI 1640 containing 25 mM Hepes (N-2hydroxyethylpiperazine-N'-2-ethanesulfonic acid), Lglutamine (BioWhittaker, Walkerswille, MD) and 0.05\% human serum albumin (Sanquin, Amsterdam, The Netherlands) (RPMI/HSA). The neutrophils were then subjected to a hypotonic shock with water for $30 \mathrm{~s}$ to lyse remaining erythrocytes.

\section{Fluorometric phagocytosis assay}

Phagocytosis was performed using Fluorescein isothiocyanate (FITC)-labelled microorganisms, MBL-deficient serum and freshly isolated human neutrophils. In brief, organisms were mixed (100/100: vol/vol) with FITC (Sigma-Aldrich, Steinheim, Germany) $(1 \mathrm{mg} / \mathrm{mL}$ in $1 \mathrm{M}$ sodium carbonate buffer, $\mathrm{pH} 9.6$ ) and incubated at $37^{\circ} \mathrm{C}$ for $1 \mathrm{~h}$ under constant shaking at $200 \mathrm{rpm}$. Organisms were washed with RPMI 1640 medium twice. For each separate experiment, organisms were cultured and labelled with FITC.

Aliquots of FITC-labelled microorganisms $(50 \mu \mathrm{l}$ of $2 \times$ $10^{6} \mathrm{cells} / \mathrm{mL}$ ) were transferred in 96-wells microtiter plates. The pellets were tumbled with 20\% MBL-deficient serum in the presence of $100 \mu \mathrm{g} / \mathrm{mL}$ anti-C1q mAb, with or without purified human MBL $(5 \mu \mathrm{g} / \mathrm{mL}$, final concentration) and incubated for $15 \mathrm{~min}$ on a shaking plate at $37^{\circ} \mathrm{C}(150 \mathrm{rev} / \mathrm{min})$. The pellet of the pre-opsonised organisms was suspended in $50 \mu \mathrm{L}$ of RPMI 1640 and incubated with $50 \mu \mathrm{L}$ purified PMNs. Phagocytosis was stopped after $15 \mathrm{~min}$ by addition of $250 \mu \mathrm{L}$ ice cold RPMI 1640 and the plate was centrifuged at $4^{\circ} \mathrm{C}$ at $1200 \mathrm{rpm}$ for $10 \mathrm{~min}$. Allophycocyanin (APC)-conjugated CD11b MAb (Becton Dickinson, San Jose, CA) served as a marker for human PMN [28] for the phagocytosis of yeast. The pellet from each well was suspended in $5 \mu \mathrm{L}(250 \mu \mathrm{g} / \mathrm{ml}$ in PBS) and was incubated at $4{ }^{\circ} \mathrm{C}$ for $30 \mathrm{~min}$, followed by the addition of $250 \mu \mathrm{L}$ of RPMI 1640 to each well and centrifugation at $4{ }^{\circ} \mathrm{C}$ at $1200 \mathrm{rpm}$ for $10 \mathrm{~min}$. The cell pellet was suspended in $250 \mu \mathrm{L}$ RPMI 1640 supplemented with $1 \%$ paraformaldehyde solution (PFA) and stored on ice for 30 min. Analysis of the samples was performed with a flow cytometer. Phagocytosis of the FITC-labelled microorganisms was evaluated by determining the proportion of labelled PMNs expressed as a percentage of the total population of PMNs. The maximum percentages, obtained within an experiment were assigned a value of $100 \%$ with all other percentages within the same experiment expressed as a relative percentage of this maximum. Negative controls for opsonophagocytosis were established by incubating organisms in RPMI 1640 containing neither serum nor purified human MBL in the opsonization step.

\section{Haemolytic MBL assay}

A haemolytic MBL assay was used to study MBL activation by different microorganisms. This assay was previously described by Kuipers et al [3] and makes use of microorganism-induced MBL activation in a dilution series of pooled human serum, followed by subsequent C5b-6mediated bystander haemolysis of chicken erythrocytes. As a surplus of all down stream components of the lectin pathway are provided by a standardized concentration of MBL-deficient serum in this assay, the complement activation by bound MBL is the rate limiting step.

In brief, different microbial concentrations were added in $50 \mu \mathrm{l}$ per well in a 96 well microtiter plate, and serially diluted in vertical rows (two-fold dilutions). As the source of MBL, human pooled serum (HPS, stored in aliquots as previously described) from healthy workers of our laboratory was diluted $1: 32$ in $\mathrm{VSB}^{2+}$ and $50 \mu \mathrm{g} / \mathrm{mL}$ anti-C1q $\mathrm{mAb}$ [26], incubated on ice for 15 minutes, and then serially diluted $\left(10^{-0.5}\right)$ in $\mathrm{VSB}^{2+}$ (final concentration of $1 / 100$ HPS). Samples $(50 \mu \mathrm{L})$ of each dilution were tested for haemolytic activity, using chicken erythrocytes $(50 \mu \mathrm{L}$ of a mixture of MBL-deficient serum and $10^{9}$ chicken erythrocytes in $\mathrm{VSB}^{2+}$ ). The microtiter plates were placed in a water bath at $37^{\circ} \mathrm{C}$ for $1 \mathrm{~h}$ and then centrifuged for 10 min, $2500 \mathrm{rpm}$. Supernatant of each sample was transferred to a flat-bottom plate containing $200 \mu \mathrm{L}$ Super Q per well. Haemoglobin release was measured in an ELISA reader at $405 \mathrm{~nm}$. Percentages of haemolysis were calculated using controls for $100 \%$ (water lysed) and $0 \%$ (buffer incubated) haemolysis. After incubation, the 
degree of bystander erythrocyte lysis was translated into the number of active sites per erythrocyte (Z-value) using the equation of Borsos and Rapp [29]. Titters were read at $\mathrm{Z}=0.300$. To measure the alternative pathway activation by the different microorganisms, the experiment $\mathrm{s}$ described above was performed with HPS in EGTA-VB (8 $\mathrm{mM}$ ethylene glycol bis-( $\beta$-aminoethyl ether)- $N, N, N^{\prime}, N^{\prime}-$ tetraacetic acit with $2.5 \mathrm{mM} \mathrm{Mg}{ }^{2+}$ ) preventing classical and lectin pathway activation by removing $\mathrm{Ca}^{2+}$. Direct haemolysis of the erythrocytes by microbial products was excluded by incubating microorganisms and erythrocytes together with MBL-deficient serum only. All experiments were repeated at least three times

\section{Statistical analysis}

Statistical significance was determined by unpaired Student's $\underline{t}$ test, using GraphPad Software program (Prism 5; GraphPad Software, Inc., San Diego, Calif.). P values of < 0.05 were considered to be statistically significant.

\section{Results}

\section{I. Binding of MBL to different pathogens}

A striking difference in binding patterns of MBL to the different microorganisms was found (Figure 1). Binding of MBL to C. albicans, C. parapsilosis and in a lesser extend to acapsular C. neoformans was found. Almost no binding of MBL was observed to $S$. aureus, E. coli and encapsulated $C$. neoformans. No binding was observed in the absence of $\mathrm{Ca}^{2+}$ (data not shown) and when purified MBL was not added.

\section{C4 and C3b deposition on the various pathogens}

With C. albicans, C. parapsilosis and of acapsular C. neoformans deposition of the cleavages product $\mathrm{C} 4$ was detected after 2 min of incubation in MBL-deficient serum and was significantly enhanced by the addition of MBL at 2 min up to $10 \min (P<0.005$ or $P<0.05$, unpaired Student' t test of MFI) (Figure 2). Deposition of C4 was maximal at 5 min, whereas in the absence of MBL C4 deposition attained its maximal amount slowly over the time course measured. In contrast, addition of purified MBL to MBLdeficient serum did not increase $\mathrm{C} 4$ deposition significantly to the capsulated strains of $C$. neoformans, S. aureus and E. coli.

Experiments with antibody to C3b (anti-C3b) showed that the addition of purified human MBL enhanced the deposition of C3b on Candida species and, to a lesser degree, C3b deposition on acapsular, encapsulated C. neoformans and S. aureus (Figure 3). With Candida species, acapsular C. neoformans and S. aureus, C3b deposition was detected after $2 \mathrm{~min}$ of incubation in serum, with enhancement of deposition in the presence of MBL, reaching significance at 5 up to $30 \mathrm{~min}$ for $C$. albicans $(P<0.05$ unpaired Student' $t$ test) and at 15 and $30 \mathrm{~min}$ for $C$. par- apsilosis, acapsular C. neoformans and S. aureus $(P<0.005$ or $P<0.05$ unpaired Student' $t$ test). An increase in C3b deposition was observed for capsulated C. neoformans, reaching significance only at $30 \mathrm{~min}(P<0.05$ unpaired Student' $t$ test).

\section{Opsonophagocytosis of different pathogens}

Opsonophagocytosis of C. albicans and C. parapsilosis was enhanced by preincubation in the presence with purified MBL compared to preincubation with MBL-deficient serum alone, reaching significance at $2.5 \%$ up to $20 \%$ serum for $C$. albicans $(P<0.05$, unpaired Student' $t$ test of $\%$ gated) and at $2.5 \%$ and $5 \%$ serum for $C$. parapsilosis ( $P$ $<0.05$, unpaired Student' $t$ test of \% gated) (Figure 4).

We noted less opsonophagocytosis in the presence with purified human MBL and the acapsular strain of C. neoformans compared to Candida spp., although significance was reached at $10 \%$ and $20 \%$ serum $(P<0.05$, unpaired Student' $t$ test of \% gated). The capsulated strain of C. neoformans showed no opsonophagocytosis with or without adding purified human MBL. S. aureus and E. coli showed no opsonophagocytosis in the lowest concentration with or without adding purified human MBL. But MBL appears to play a role in the higher serum concentrations, reaching a significance at $20 \%$ serum for $S$. aureus $(P<0.005$, unpaired Student' $t$ test of \% gated). When downstream complement components were inactivated by heating at $56^{\circ} \mathrm{C}$, opsonophagocytosis was eliminated under all conditions tested (data not shown).

\section{Haemolytic assessment of complement activity via the lectin pathway}

The haemolytic assay was used to characterize the different microorganisms as a weak or potent activator of the MBL arm of the complement system at a 1/32 dilution of HPS, since no activation of the alternative pathway was observed with this dilution (data not shown). In this assay, the number of microbes and the MBL concentration were varied. Addition of the inhibitory antibody directed against $\mathrm{C} 1 \mathrm{q}$ eliminated the contribution of the classical pathway. The following organisms were ranked, in order of decreasing MBL-activating ability, S. cerevisiae, C. albicans, C. parapsilosis, encapsulated, and acapsular strain of C. neoformans and S. aureus and E. coli (Table 1). The C. neoformans strains, $S$. aureus strains, E. coli strains did not activate MBL at this serum concentration.

\section{Discussion}

Mannose binding lectin (MBL), is a calcium-dependent plasma lectin that binds a wide range of microorganisms [5]. In the present study, we evaluated the role of binding of MBL at the subsequent deposition of $\mathrm{C} 4$ and $\mathrm{C} 3 \mathrm{~b}$ on the microbial cell wall. Also the role of MBL in opsonophagocytosis by PMN was studied. Well-character- 


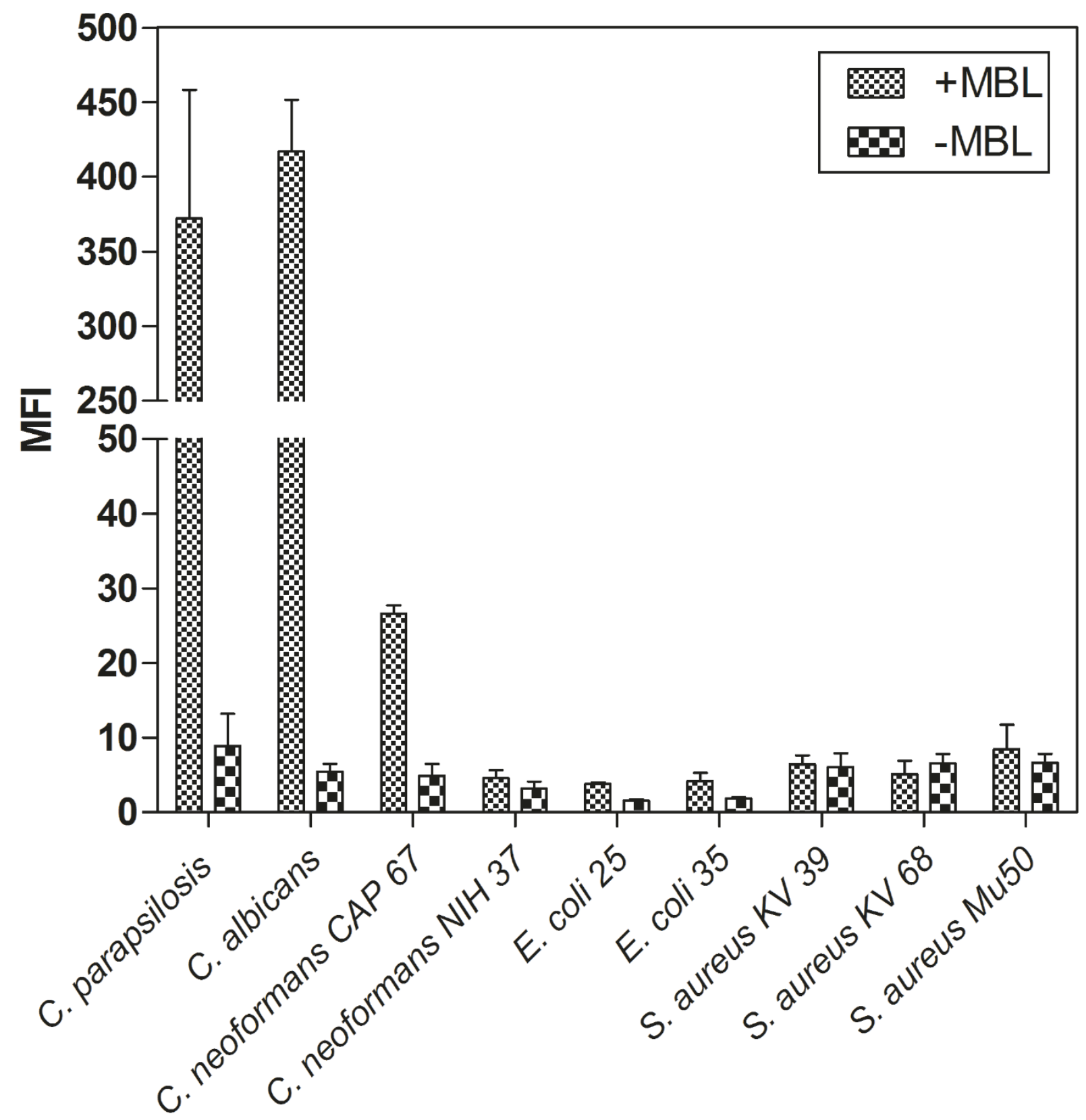

Figure I

Ca2+-dependent interaction between mannose-binding lectin (MBL) and C. parapsilosis and reference strains C. albicans, C. neoformans, S. aureus and E. coli. Microorganisms were incubated in the presence of $5 \mu \mathrm{g} / \mathrm{mL}$ purified human MBL in $\mathrm{VSB}^{2+}$. After incubation with mouse anti-MBL monoclonal antibody and FITC-labeled goat anti mouse IgG, binding of MBL to these microorganisms was analyzed by flow cytometry. Results are expressed as median fluorescence intensity (MFI). Data are the mean \pm SEM of 3 separate experiments. Solid bars, addition of human purified MBL; open bars, no addition of human purified MBL. 

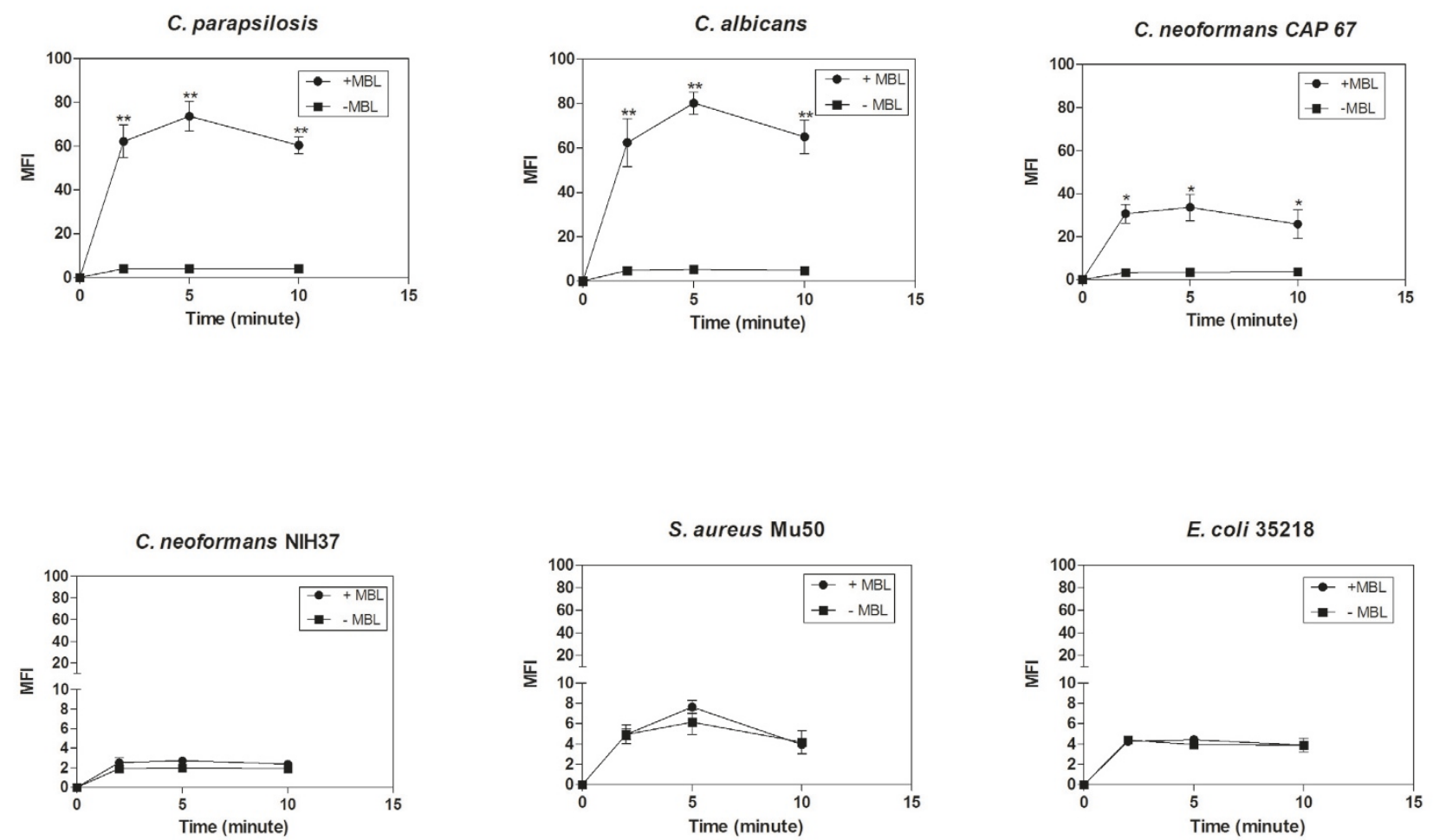

\section{Figure 2}

Time-dependent $C 4$ deposition on $C$. parapsilosis and reference strains $C$. albicans, $C$. neoformans, S. aureus and $E$. coli in MBL-deficient serum supplemented with exogenous purified human MBL. Microorganisms were incubated with $10 \% \mathrm{MBL}$-deficient serum with or without $2.5 \mu \mathrm{g} / \mathrm{mL}$ purified human $\mathrm{MBL}$, at $37^{\circ} \mathrm{C}$ over a time course of $10 \mathrm{~min}$. Results are expressed as median fluorescence (MFI). Data are the mean \pm SEM of 3 separate experiments. $* P<0.05$ and $* * P<$ 0.005 unpaired Student's $t$ test of MFI.

ized C. parapsilosis strain, C. albicans, E. coli, S. aureus and C. neoformans were used. These data demonstrate that MBL binds to C. parapsilosis, C. albicans and acapsular $C$. neoformans. MBL binding leads to activation of the lectin pathway of complement, demonstrated by deposition of C4 and C3 fragments and to enhanced opsonophagocytosis by PMNs. MBL is an important opsonin for phagocytosis of Candida species and acapsular C. neoformans. It lacks the function as an opsonin for phagocytosis of encapsulated C. neoformans. Indeed, MBL plays a much less important role in the process of opsonisation of the $S$. aureus and $E$ coli strains used. The lack of MBL activation of $S$. aureus, E. coli and C. neoformans could be advantageous to the organism in allowing it to remain hidden from the MBL arm of the complement system (i.e., protected from lectin pathway-induced complement activation). Serum MBL levels would be unlikely to influence these organisms colonization/infection, compared to the yeast, which are strong activators of the MBL arm of the complement system. These data suggest the importance of MBL in the first-line defence against Candida species and acapsular $C$. neoformans.

Previously, studies have shown that MBL binds with high avidity to C. albicans and C. parapsilosis as well as to encapsulated C. neoformans, through mannan, a major component of fungal cell walls [4,30,31]. Microorganisms, as observed in the present study, fall into three groups. $S$. aureus, E. coli and encapsulated C. neoformans did not bind to $\mathrm{MBL}$, acapsular C. neoformans bound MBL only weakly and both Candida species showed strong MBL binding. MBL has recently been shown to bind to C. albicans via its lectin domain, resulting in fungi agglutination on their hyphea outgrowths [9].

Capsules have an important role in protecting organisms in vivo against complement attack, by making them resistant to phagocytosis $[13,32]$. The acapsular form of $C$. neoformans has exposed carbohydrate residues on its surface that are suitable for interaction with lectin-like receptors 

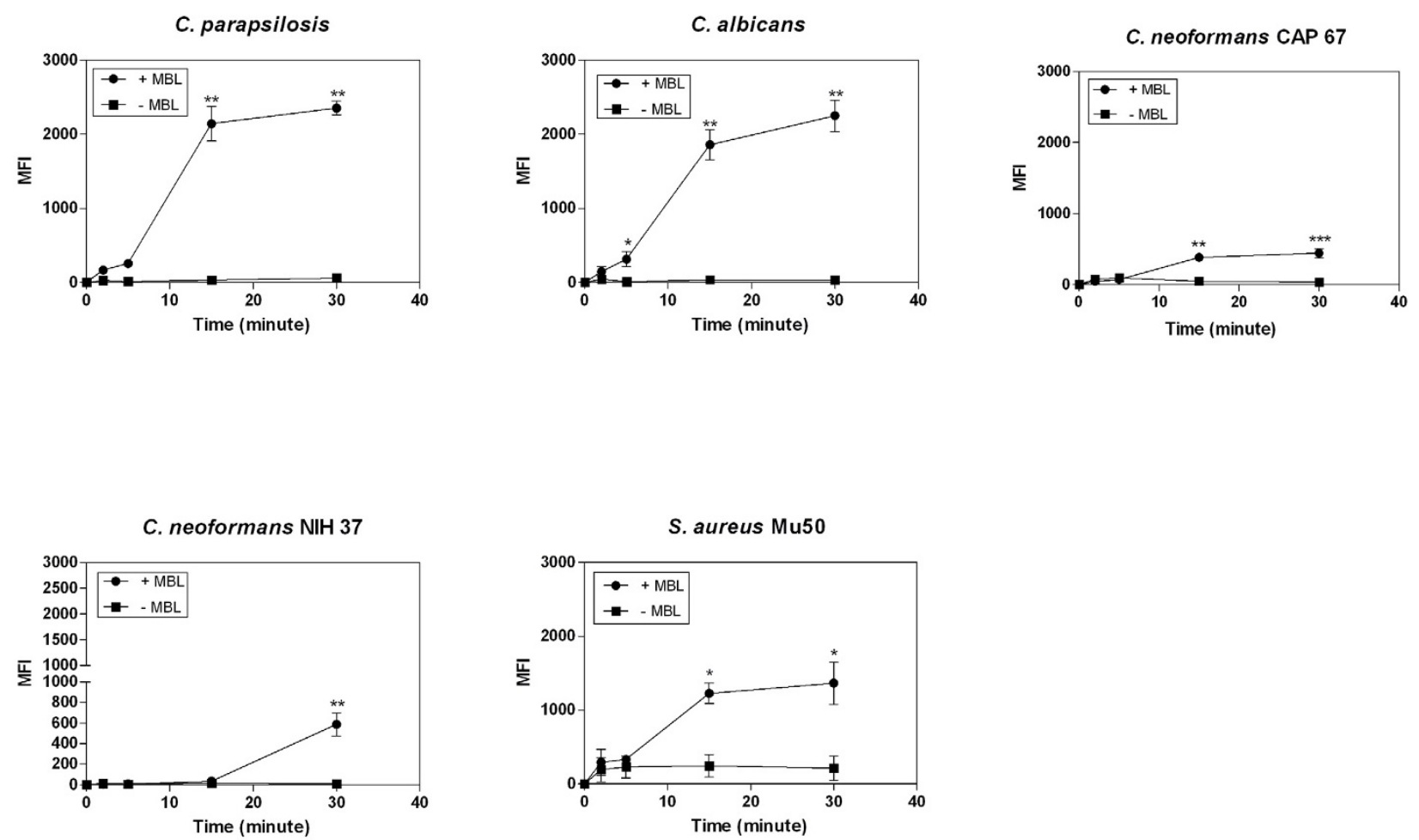

Figure 3

Time-dependent C3b deposition on C. parapsilosis and reference strains $C$. albicans, $C$. neoformans, S. aureus and $E$. coli in MBL-deficient serum supplemented with exogenous purified human MBL. Microorganisms were incubated with $10 \% \mathrm{MBL}$-deficient serum with or without $2.5 \mu \mathrm{g} / \mathrm{mL}$ purified human $\mathrm{MBL}$, at $37^{\circ} \mathrm{C}$ for $30 \mathrm{~min}$. Results are expressed as median fluorescence (MFI). Data are the mean \pm SEM of 3 separate experiments. $* P<0.05$ and $* * P<0.005$ unpaired Student's $t$ test of MFI.

[30]. Thus, the levels of MBL required for opsonophagocytosis may depend on the availability of binding epitopes on the infectious agents.

The opsonophagocytosis assay and the complement-deficient sera used in these experiments allowed us to measure MBL dependent opsonization, because the classical pathway was blocked with anti-C1q [7]. MBL increased the uptake of C. albicans, C. parapsilosis andacapsular C. neoformans by PMNs in serum. Since phagocytosis was not observed by binding of MBL in the absence of downstream complement factors (data not shown), phagocytosis was enhanced via C3b-dependent opsonization recognized by complement receptors on PMNs. Thus, MBL is an opsonin only in the presence of complement.

In contrast to our results, Ip and Lau [9], using dendritic cells, reported that $\mathrm{MBL}$ binding does not lead to opsonophagocytosis, possibly due to the interference of MBL with the recognition of C. albicans by C-type receptors on dendritic cells, which mediate phagocytosis. Neth et al. [33] demonstrated that an MBL-mediated increases in opsonic C3 fragments enhanced opsonophagocytosis of $S$. aureus by neutrophils. However, Cunnion et al. [34] showed similar to us, that MBL-mediated complement activation, did not enhance $S$. aureus phagocytosis. They used hypo- $\gamma$-globulin serum, which had been affinitydepleted of MBL, whereas Neth et al. [33] used serum from adult individuals who were genetically deficient in $\mathrm{MBL}$, but which could contain immunoglobulins. Bacterial strain differences could account for the differences find in these reports [4]. Comparable to our results with E. coli, previous experiments also have shown that $\mathrm{MBL}$ contributed little to opsonophagocytosis of gram-negative microorganisms [35-37]. Recently, Brouwer et al. [38] reported MBL binding on the surface of $S$. pneumoniae, $S$. aureus and E. coli, but did not observe any significant contribution of MBL to opsonophagocytosis of these organisms. Comparable to our results, Brouwer et al. [38] indicates that the lectin pathway of complement activation did not contribute to a large extent of the opsonophagocytosis of these bacteria. 

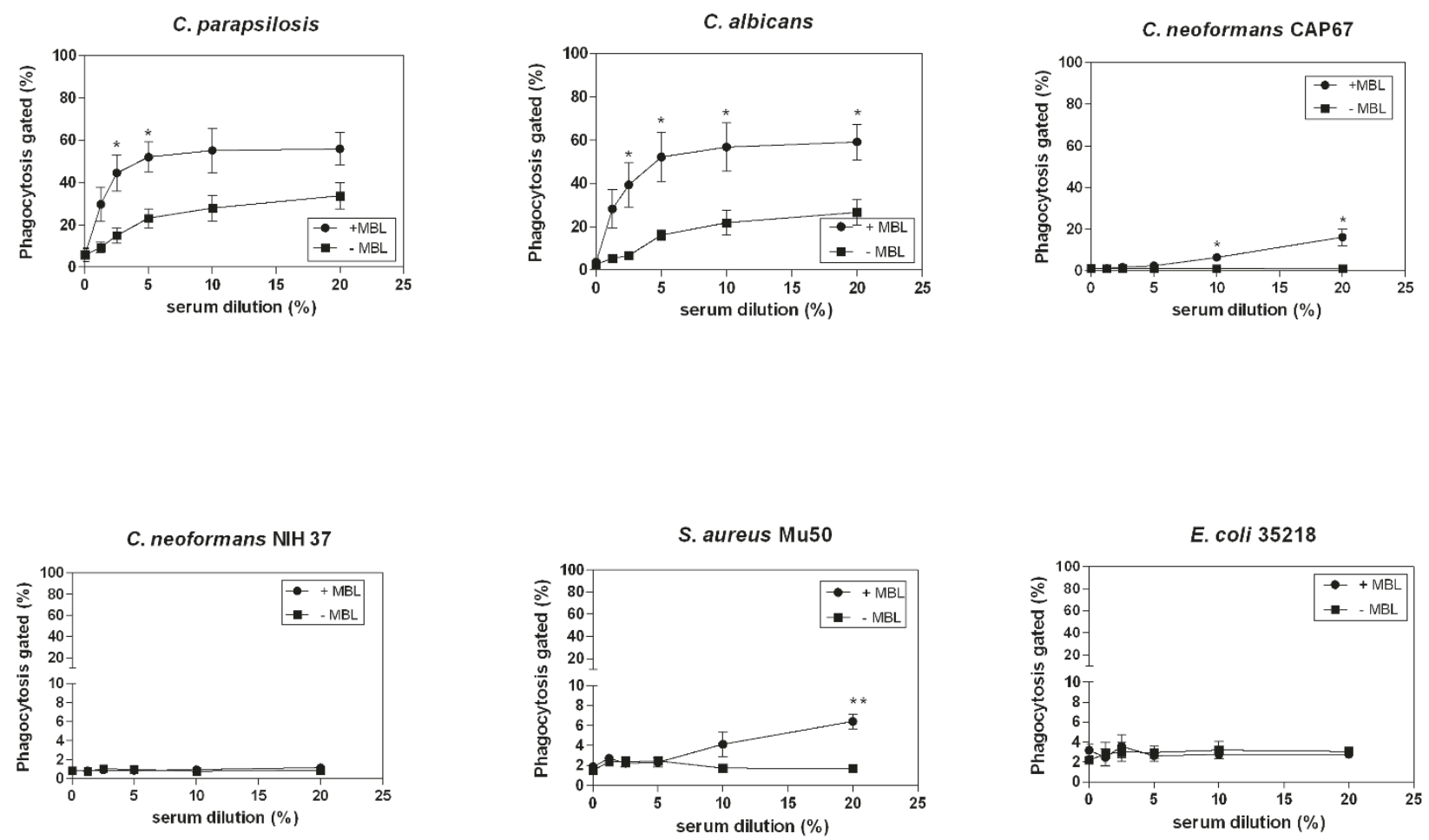

Figure 4

Opsonophagocytosis of C. parapsilosis and reference strains C. albicans, C. neoformans, S. aureus and E. coli by human polymorphonuclear (PMN) cells. Microorganisms were labelled with fluorescein isothiocyanate (FITC) and preincubated in the absence (control) or presence of $20 \%$ mannose-binding lectin (MBL)-deficient serum supplemented with $5 \mu \mathrm{g} /$ $\mathrm{mL}$ human purified MBL, for $20 \mathrm{~min}$. The yeast:phagocyte ratio was 2:I. Phagocytosis was analyzed by the use of flow cytometry and expressed as percentage of microorganisms-ingested PMN. Data are the mean \pm SEM of 3 separate experiments. *P < 0.05 and $* * P<0.005$ unpaired Student's $t$ test of phagocytosis \% gated.

Also it was shown that in MBL transgenic mice MBL plays an important role in the innate immunity [39]. In contrast to our observations, Shi et al. [40] reported that MBL-initiated opsonophagocytosis by both neutrophils and macrophages is an important first-line host defence against $S$. aureus in mice. Mice that do not have a functional MBL complement pathway are highly susceptible to infection with $S$. aureus. In that study, decreased phagocytosis of $S$. aureus by peritoneal macrophages in MBL-null mice was reported [40]. However, we only did in vitro studies, which may or may not explain the susceptibilities of MBL deficient individuals to these organisms. Further studies are needed to define the role of MBL in the defence against these bacteria.

Previously, it has shown, that Neisseria meningitidis, the causative agent of meningococcal disease, is a strong activator of MBL [3]. This is in line with clinical studies, which showed that MBL is associated with an increased risk of mucosal acquired infections including meningococcal disease [41]. However, the role of MBL as an opsonin may thus critically depend on the microbial species involved, interspecies variation and the type of phagocytes present.

A number of clinical studies have reported that MBL deficiency predisposes to Candida infections. Recently, Till et al. [42] described that patients with peritonitis with an early abdominal yeast infection, most commonly caused by C. albicans and C. parapsilosis [43], had lower MBL plasma levels than patients without such abdominal yeast infections. The incidence of abdominal yeast infections in patient with MBL variant genotype was significantly higher to those with no MBL variant genotype [42].

MBL present in the vaginal cavity has been found to act as recognition molecules for $C$. albicans that colonize the cervicovaginal mucosa, which suggest that the lectin pathway plays an important role against Candida infection [44]. 
Table I: Differential lectin pathway activating properties of S. cerevisiae, C. albicans, C. parapsilosis, C. neoformans, E. coli and S. aureus via MBL

\begin{tabular}{lc}
\hline Microbial strain & Concentration at Z $=\mathbf{0 . 3}$ (CFU/well) \\
\hline S. cerevisiae & $3.39 \times 10^{5}$ \\
\hline C. albicans & $4.0 \times 10^{5}$ \\
\hline C. parapsilosis & $4.9 \times 10^{6}$ \\
\hline C. neoformans encapsulated & $>1 \times 10^{7}$ \\
\hline C. neoformans acapsular & $>1 \times 10^{7}$ \\
\hline E. coli & $>1 \times 10^{8}$ \\
\hline S. aureus & $>1 \times 10^{8}$ \\
\hline
\end{tabular}

$\mathrm{Z}$ value stands for the amount of haemolysis in the haemolytic assay, a measure of the mean number of MBL activating sites per chicken erythrocyte. CFU: Colony-forming units

Low levels of vaginal MBL in patients with recurrent vulvovaginal candidiasis (VVC) might predispose to Candida infections [45]. It has been proposed that MBL activity is critical in early life, when maternally acquired protection is decreasing and actively acquired immunity is still low $[5,39,46]$. MBL plasma concentrations at birth may be low due to both gene-polymorphisms and younger gestational age [47-49]. Thus MBL activity may play an important role in innate defence of $C$. parapsilosis in premature babies.

\section{Conclusion}

In conclusion, the present study demonstrated the important role of MBL-mediated complement activation in opsonophagocytosis of C. parapsilosis, C. albicans and acapsular C. neoformans. MBL enhances opsonization of C. parapsilosis, C. albicans and acapsular C. neoformans, via the lectin pathway, which depends on the presence and availability of MBL binding epitopes. The binding of MBL by these yeasts and subsequent complement activation and opsonophagocytosis observed in our study may explain the observed increased risk of infections caused by these microorganisms in MBL-deficient individuals.

\section{Authors' contributions}

AE participated in the design of the study, carried out the experiments and drafted the manuscript; HA participated in the design of the study and coordination; SJ carried out the experiment; $\mathrm{HB}$ participated in the design of the haemolytic assay; VJ conceived of the study, participated in its design and coordination. All authors read and approved the final manuscript.

\section{Acknowledgements}

The authors thank David Stevens (Division of Infectious Diseases, Santa Clara Valley Medical Centre, and California Institute for Medical Research,
San Jose, and Division of Infectious Diseases and Geographic Medicine, Stanford University, Stanford, CA, USA) for providing C. parapsilosis isolates, Roel Terluin (Wageningen) for providing the chicken erythrocytes and Piet Aerts (Eijkman-Winkler Institute for Medical \& Clinical Microbiology and, Utrecht University Hospital).

\section{References}

I. Brouwer N, Dolman KM, van Zwieten R, Nieuwenhuys E, Hart M, Aarden LA, Roos D, Kuijpers TW: Mannan-binding lectin (MBL)mediated opsonization is enhanced by the alternative pathway amplification loop. Mol Immunol 2006, 43( I 3):205 I-2060.

2. Ezekowitz RA: Role of the mannose-binding lectin in innate immunity. J Infect Dis 2003, I 87(Suppl 2):S335-339.

3. Kuipers S, Aerts PC, van Dijk H: Differential microorganisminduced mannose-binding lectin activation. FEMS Immunol Med Microbiol 2003, 36( I-2):33-39.

4. Neth O, Jack DL, Dodds AW, Holzel H, Klein NJ, Turner MW: Mannose-binding lectin binds to a range of clinically relevant microorganisms and promotes complement deposition. Infect Immun 2000, 68(2):688-693.

5. Turner MW: The role of mannose-binding lectin in health and disease. Mol Immunol 2003, 40(7):423-429.

6. Laursen I: Mannan-binding lectin (MBL) production from human plasma. Biochem Soc Trans 2003, 3 I (Pt 4):758-762.

7. Degn SE, Thiel S, Jensenius JC: New perspectives on mannanbinding lectin-mediated complement activation. Immunobiology 2007, 2 I 2(4-5):30 I-3 I I.

8. Jack DL, Turner MW: Anti-microbial activities of mannosebinding lectin. Biochem Soc Trans 2003, 3 I (Pt 4):753-757.

9. Ip WK, Lau YL: Role of mannose-binding lectin in the innate defense against Candida albicans: enhancement of complement activation, but lack of opsonic function, in phagocytosis by human dendritic cells. J Infect Dis 2004, I90(3):632-640.

10. Dommett RM, Klein N, Turner MW: Mannose-binding lectin in innate immunity: past, present and future. Tissue Antigens 2006, 68(3): 193-209.

II. Turner MW: The lectin pathway of complement activation. Res Immunol 1996, I47(2): I I0-I I5.

12. Turner MW, Hamvas RM: Mannose-binding lectin: structure, function, genetics and disease associations. Rev Immunogenet 2000, 2(3):305-322.

13. Panepinto JC, Komperda KW, Hacham M, Shin S, Liu X, Williamson PR: Binding of Serum Mannan Binding Lectin to a Cell Integrity-Defective Cryptococcus neoformans ccr4\{Delta\} Mutant. Infect Immun 2007, 75(1 0):4769-4779.

14. Granell M, Urbano-Ispizua A, Suarez B, Rovira M, Fernandez-Aviles F, Martinez C, Ortega M, Uriburu C, Gaya A, Roncero JM, et al.: Mannan-binding lectin pathway deficiencies and invasive fungal 
infections following allogeneic stem cell transplantation. Exp Hematol 2006, 34( I 0): I 1435-I44|

15. Eisen DP, Minchinton RM: Impact of mannose-binding lectin on susceptibility to infectious diseases. Clin Infect Dis 2003, 37(II): I496-I505.

16. Pfaller MA, Jones RN, Doern GV, Fluit AC, Verhoef J, Sader HS, Messer SA, Houston A, Coffman S, Hollis RJ: International surveillance of blood stream infections due to Candida species in the European SENTRY Program: species distribution and antifungal susceptibility including the investigational triazole and echinocandin agents. SENTRY Participant Group (Europe). Diagn Microbiol Infect Dis 1999, 35(I):19-25.

17. Pfaller MA, Jones RN, Doern GV, Sader HS, Messer SA, Houston A, Coffman S, Hollis RJ: Bloodstream infections due to Candida species: SENTRY antimicrobial surveillance program in North America and Latin America, 1997-1998. Antimicrob Agents Chemother 2000, 44(3):747-75I.

18. Sandven P: Epidemiology of candidemia. Rev Iberoam Micol 2000 I7(3):73-8|

19. Sarvikivi E, Lyytikainen O, Soll DR, Pujol C, Pfaller MA, Richardson M, Koukila-Kahkola P, Luukkainen P, Saxen $\mathrm{H}$ : Emergence of fluconazole resistance in a Candida parapsilosis strain that caused infections in a neonatal intensive care unit. J Clin Microbiol 2005, 43(6):2729-2735

20. Levin AS, Costa SF, Mussi NS, Basso M, Sinto SI, Machado C, Geiger DC, Villares MC, Schreiber AZ, Barone AA, et al:: Candida parapsilosis fungemia associated with implantable and semiimplantable central venous catheters and the hands of healthcare workers. Diagn Microbiol Infect Dis 1998 30(4):243-249.

21. Levy I, Rubin LG, Vasishtha S, Tucci V, Sood SK: Emergence of Candida parapsilosis as the predominant species causing candidemia in children. Clin Infect Dis 1998, 26(5): 1086-1088.

22. Weems | J Jr, Chamberland ME, Ward J, Willy M, Padhye AA, Solomon SL: Candida parapsilosis fungemia associated with parenteral nutrition and contaminated blood pressure transducers. Clin Microbiol I 987, 25(6): 1029-1032.

23. Krcmery V, Barnes AJ: Non-albicans Candida spp. causing fungaemia: pathogenicity and antifungal resistance. J Hosp Infect 2002, 50(4):243-260.

24. Lee SJ, Gonzalez-Aseguinolaza G, Nussenzweig MC: Disseminated candidiasis and hepatic malarial infection in mannose-binding-lectin-A-deficient mice. Mol Cell Biol 2002, 22(23):8199-8203.

25. Omtvedt LA, Royle L, Husby G, Sletten K, Radcliffe CM, Harvey DJ, Dwek RA, Rudd PM: Glycan analysis of monoclonal antibodies secreted in deposition disorders indicates that subsets of plasma cells differentially process IgG glycans. Arthritis Rheum 2006, 54(I I):3433-3440.

26. McGrath FD, Brouwer MC, Arlaud G], Daha MR, Hack CE, Roos A: Evidence that complement protein $\mathrm{Clq}$ interacts with $\mathrm{C}$ reactive protein through its globular head region. I Immunol 2006, I 76(5):2950-2957.

27. Troelstra A, Giepmans BN, van Kessel KP, Lichenstein HS, Verhoef J, van Strijp JA: Dual effects of soluble CDI4 on LPS priming of neutrophils. J Leukoc Biol 1997, 6I(2): 173-I78.

28. van Spriel $A B$, Herik-Oudijk IE van den, van Sorge NM, Vile HA, van Strijp JA, Winkel JG van de: Effective phagocytosis and killing of Candida albicans via targeting FcgammaRI (CD64) or FcalphaRI (CD89) on neutrophils. J Infect Dis 1999, I 79(3):66I-669.

29. Borsos T, Rapp HJ: Chromatographic Separation of the First Component of Complement and Its Assay on a Molecular Basis. J Immunol 1963, 91:851-858.

30. Cross CE, Bancroft G]: Ingestion of acapsular Cryptococcus neoformans occurs via mannose and beta-glucan receptors, resulting in cytokine production and increased phagocytosis of the encapsulated form. Infect Immun 1995, 63(7):2604-26II.

31. Ikeda R, Saito F, Matsuo M, Kurokawa K, Sekimizu K, Yamaguchi M, Kawamoto S: Contribution of the mannan backbone of cryptococcal glucuronoxylomannan and a glycolytic enzyme of Staphylococcus aureus to contact-mediated killing of Cryptococcus neoformans. J Bacteriol 2007, I 89(13):48|5-4826.

32. Buchanan KL, Murphy JW: What makes Cryptococcus neoformans a pathogen? Emerg Infect Dis 1998, 4(I):7I-83.

33. Neth O, Jack DL, Johnson M, Klein NJ, Turner MW: Enhancement of complement activation and opsonophagocytosis by com- plexes of mannose-binding lectin with mannose-binding lectin-associated serine protease after binding to Staphylococcus aureus. J Immunol 2002, I69(8):4430-4436.

34. Cunnion KM, Zhang HM, Frank MM: Availability of complement bound to Staphylococcus aureus to interact with membrane complement receptors influences efficiency of phagocytosis. Infect Immun 2003, 7 I(2):656-662.

35. Zhao L, Ohtaki Y, Yamaguchi K, Matsushita M, Fujita T, Yokochi T, Takada $\mathrm{H}$, Endo $\mathrm{Y}$ : LPS-induced platelet response and rapid shock in mice: contribution of O-antigen region of LPS and involvement of the lectin pathway of the complement system. Blood 2002, 100(9):3233-3239.

36. Selander B, Martensson U, Weintraub A, Holmstrom E, Matsushita M, Thiel S, Jensenius JC, Truedsson L, Sjoholm AG: Mannan-binding lectin activates $\mathrm{C} 3$ and the alternative complement pathway without involvement of C2. J Clin Invest 2006, I I 6(5): I 425- I 434.

37. Li K, Sacks SH, Sheerin NS: The classical complement pathway plays a critical role in the opsonisation of uropathogenic Escherichia coli. Mol Immunol 2008, 45(4):954-962.

38. Brouwer N, Dolman KM, van Houdt M, Sta M, Roos D, Kuijpers TW: Mannose-binding lectin (MBL) facilitates opsonophagocytosis of yeasts but not of bacteria despite MBL binding. J Immunol 2008, I 80(6):4|24-4|32.

39. Tabona P, Mellor A, Summerfield JA: Mannose binding protein is involved in first-line host defence: evidence from transgenic mice. Immunology 1995, 85(I):153-159.

40. Shi L, Takahashi K, Dundee J, Shahroor-Karni S, Thiel S, Jensenius JC, Gad F, Hamblin MR, Sastry KN, Ezekowitz RA: Mannose-binding lectin-deficient mice are susceptible to infection with Staphylococcus aureus. J Exp Med 2004, I 99( I0):1379-1390.

4I. Jack DL, Lee ME, Turner MW, Klein NJ, Read RC: Mannose-binding lectin enhances phagocytosis and killing of Neisseria meningitidis by human macrophages. J Leukoc Biol 2005, 77(3):328-336.

42. van Till JW, Modderman PW, de Boer M, Hart MH, Beld MG, Boermeester MA: Mannose-binding lectin deficiency facilitates abdominal Candida infections in patients with secondary peritonitis. Clin Vaccine Immunol 2008, I 5(I):65-70.

43. Chen KH, Chang CT, Yu CC, Huang JY, Yang CW, Hung CC: Candida parapsilosis peritonitis has more complications than other Candida peritonitis in peritoneal dialysis patients. Ren Fail 2006, 28(3):24I-246.

44. Pellis V, De Seta F, Crovella S, Bossi F, Bulla R, Guaschino S, Radillo $\mathrm{O}$, Garred P, Tedesco F: Mannose binding lectin and C3 act as recognition molecules for infectious agents in the vagina. Clin Exp Immunol 2005, I39(1):120-126.

45. Liu F, Liao Q, Liu Z: Mannose-binding lectin and vulvovaginal candidiasis. Int J Gynaecol Obstet 2006, 92(I):43-47.

46. Turner MW: Mannose-binding lectin: the pluripotent molecule of the innate immune system. Immunol Today 1996, I 7(I I):532-540.

47. Lau YL, Chan SY, Turner MW, Fong J, Karlberg J: Mannose-binding protein in preterm infants: developmental profile and clinical significance. Clin Exp Immunol 1995, 102(3):649-654.

48. Hilgendorff A, Schmidt R, Bohnert A, Merz C, Bein G, Gortner L: Host defence lectins in preterm neonates. Acta Paediatr 2005, 94(6):794-799.

49. Frakking FN, Brouwer N, Zweers D, Merkus MP, Kuijpers TW, Offringa M, Dolman KM: High prevalence of mannose-binding lectin (MBL) deficiency in premature neonates. Clin Exp Immunol 2006, I45(I):5-12. 